\title{
Avaliação durante operação de sistemas de água não potável em edifícios residenciais
}

\author{
Evaluation during operation of non-potable water systems \\ in residential buildings
}

\section{Carolina Paula de Castilho Lúcia Helena de Oliveira}

\section{Resumo}

A

tualmente é observado um crescimento de iniciativas independentes para a implantação de sistemas prediais de água não potável em edifícios residenciais. Essas iniciativas contam com pouco respaldo técnico normativo, diretrizes ou legislação que orientem projetistas, executores e gestores sobre as práticas adequadas de implantação, operação e manutenção desses sistemas, o que pode colocar em risco a saúde dos usuários e o sucesso dessa tecnologia. Considerando-se que é indispensável atender às necessidades dos usuários por meio da adequação das soluções ao uso, a Avaliação Durante Operação (ADO) apresenta-se como uma ferramenta adequada para a análise da situação atual do sistema. Nesse contexto, este artigo tem como objetivo avaliar o desempenho de sistemas prediais de água não potável durante sua operação em edifícios residenciais no que se refere a projeto, execução, operação e manutenção. Para tanto foi aplicada a metodologia de ADO em seis edifícios residenciais. Os resultados mostram que a falta de capacitação técnica, de normas técnicas e de legislações específicas que orientem projetistas, executores, gestores e usuários contribui para o atual cenário, caracterizado por sistemas que operam com desempenho inferior para atender às necessidades e garantir a segurança dos usuários.

Palavras-chave: Sistema predial de água não potável. Desempenho. Avaliação Durante Operação (ADO). Água de reúso.

\begin{abstract}
There is currently a noticeable increase in independent initiatives for the implementation of non-potable water systems in residential buildings. These initiatives count on little technical support, regulatory guidelines or legislation to guide designers, builders and managers on the appropriate practices of implementation, operation and maintenance of these systems, which can put at risk both the health of users and the success of this technology. Considering that it is essential to meet the needs of users, adapting solutions to use, evaluation during operation (EDO) is a suitable tool for the analysis of the system's current situation. Hence, this study aims to evaluate the performance of buildings' non-

potable water systems during their operation in residential buildings, with regard to design, implementation, operation and maintenance. The EDO method was applied in six residential buildings. The results show that lack of technical training, specific technical requirements and laws to guide designers, builders, managers and users contributes to the current scenario, characterized by systems that operate with less than adequate performance to meet the needs of users and ensure their safety.
\end{abstract}

Carolina Paula de Castilho Universidade de São Paulo São Paulo - SP - Brasil

Lúcia Helena de Oliveira Universidade de São Paulo São Paulo - SP - Brasil

Recebido em 22/07/16 Aceito em 01/12/16
Keywords: Non-potable water system. Performance. Evaluation During Operation (EDO). Water reuse. 


\section{Introdução}

O crescimento populacional, a urbanização, os movimentos migratórios e a industrialização, acompanhados do crescimento da produção e do consumo, geram aumento constante de demanda por água e impacto sobre as fontes naturais desse recurso (UNITED..., 2015).

Associada ao aumento da demanda, a escassez de água nas áreas metropolitanas é cada vez mais presente. Nesse contexto o uso de água não potável é uma realidade não apenas como fonte alternativa de suprimento para regiões que vivenciam a escassez, como para evitar os altos custos de tratamento previamente ao descarte de efluentes em águas superficiais. Independentemente do fator, quer seja econômico, político ou socioambiental, novas tecnologias para sistemas de tratamento de água vêm sendo desenvolvidas com o objetivo de oferecer opções adequadas à atividade-fim de sistemas prediais hidráulicos (CASTILHO, 2016).

Embora a água para uso urbano corresponda à maior parte da demanda, a experiência com o uso de água não potável no Brasil ainda é recente e, ao contrário de diversos estados norte-americanos (UNITED..., 2012), de países do Mediterrâneo e da União Europeia (MEDITERRANEAN..., 2007), de países árabes (ARAB..., 2010) e da Austrália (POWER, 2010), não dispõe de diretrizes na forma de boas práticas, guias técnicos e legislação.

No Brasil a implantação de sistemas de água não potável em edifícios residenciais e de escritórios não contam com respaldo técnico normativo, diretrizes ou legislação que orientem gestores, executores e profissionais sobre as práticas adequadas de implantação, gestão e monitoramento desse tipo de sistema, o que coloca em risco a segurança dos usuários e o sucesso da tecnologia (OLIVEIRA, 2009; OLIVEIRA et al., 2014). Nesse sentido, Cook, Sharma e Gurung (2014) ressaltam que a análise comparativa de desempenho de sistemas de água não potável tem estimulado muitos edifícios comerciais a implementar fontes alternativas de água, no entanto se observa carência de monitoramento para validar o desempenho desses sistemas.

Assim, este artigo tem como objetivo apresentar os resultados de uma avaliação de desempenho de sistemas de água não potável de seis edifícios residenciais realizada por meio da Avaliação Durante Operação (ADO), proposta por Almeida (1994), de modo a indicar as falhas mais frequentes e a contribuir para a redução de insucessos dos sistemas.

\section{Sistemas prediais de água não potável: desempenho e avaliação durante a operação}

Nesta seção são apresentados os conceitos de sistemas prediais de água não potável para diferentes tipos de afluentes, os requisitos de desempenho para esses sistemas e o conceito de Avaliação Durante Operação (ADO).

A água residuária, a água pluvial, a água subterrânea e a água clara são fontes de água não potável que, após a estação de tratamento, se transformam em diferentes tipos de água não potável com qualidade adequada às atividades-fins, denominadas respectivamente em função da fonte água recuperada, água pluvial, água subterrânea e água clara (OLIVEIRA; MARQUES, 2014).

A água residuária, denominada como o efluente gerado após o uso da água em edificações, pode ser classificada em água negra e água cinza. A água negra corresponde à água residuária proveniente de bacias sanitárias, mictórios, pias de cozinha e máquinas de lavar louça, enquanto a água cinza se refere ao efluente gerado pelos demais aparelhos sanitários. A água clara corresponde ao efluente gerado por sistema de resfriamento, sistema de vapor e condensador, sistema de destilação e outros equipamentos (OLIVEIRA; MARQUES, 2014).

A partir das quatro fontes de água não potável, Oliveira e Marques (2014) apresentam a classificação de quatro tipos de sistemas prediais de água não potável, esquematizados na Figura 1: o sistema predial de água não potável recuperada (SPANP-R), o sistema predial de água não potável pluvial (SPANP-P), o sistema predial de água não potável subterrânea (SPANP-S) e o sistema predial de água não potável clara (SPANP-C).

O SPANP é o conjunto de tubulações, reservatórios, equipamentos e componentes utilizados na coleta, armazenamento, tratamento de água de fonte alternativa e distribuição de água não potável.

No SPANP-R a fonte de água é a residuária, e a água distribuída é a recuperada, cujo objetivo é reduzir o consumo de água potável e o volume de efluente para a rede de esgoto sanitário.

No SPANP-P a fonte de água é a pluvial, e a água distribuída é a pluvial tratada, cujo objetivo é reduzir o consumo de água potável e amortecer as vazões no sistema de drenagem urbana. 
Figura 1 - Sistemas prediais de água não potável com diferentes fontes e usos no edifício

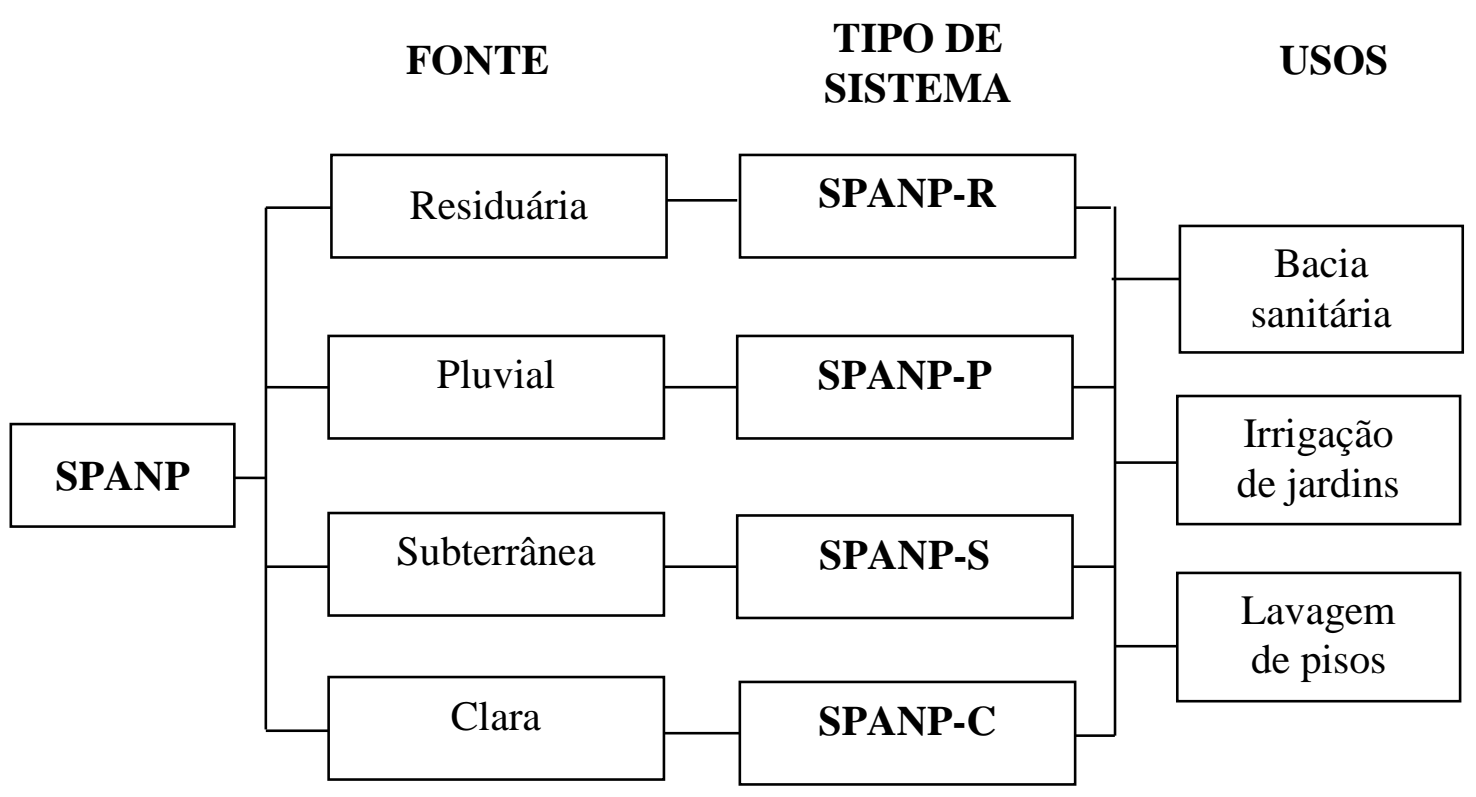

Fonte: Oliveira e Marques (2014).

No SPANP-S a fonte de água é a subterrânea, e a água distribuída é a subterrânea tratada, com o objetivo de reduzir o consumo de água potável.

No SPANP-C a fonte de água é clara, e a água distribuída é a água clara tratada, com o objetivo de reduzir a demanda de água potável.

Ressalta-se que a qualidade da água tratada varia em função do tipo de uso a ser realizado no edifício e, em função da qualidade da água da fonte, pode ter ou não tratamento.

Nesse contexto, este artigo avalia o desempenho durante a operação do sistema predial de água não potável recuperada (SPANP-R), do sistema predial de água não potável pluvial (SPANP-P) e do sistema predial de água não potável subterrânea (SPANP-S) de edifícios residenciais. Apresentamse a seguir os requisitos de desempenho dos sistemas prediais de água não potável e os conceitos de Avaliação Durante Operação.

\section{Requisitos de desempenho aplicáveis aos sistemas prediais de água não potável}

Embora existam diversas normas específicas para sistemas prediais hidráulicos, os sistemas prediais de água não potável dispõem de pouco respaldo de referências normativas brasileiras. Alguns dos requisitos do sistema predial de água potável se aplicam ao SPANP, porém há outras especificidades e cuidados que precisam ser considerados para assegurar o desempenho desse tipo de sistema e a segurança dos usuários. Essas particularidades do SPANP não são abordadas com clareza nas recomendações técnicas atualmente disponíveis.

A NBR 15575 (ABNT, 2013) menciona o SPANP na parte 1, em “Adequação ambiental”, e estabelece o requisito "Utilização e reúso de água”, recomendando em nota que as instalações hidrossanitárias privilegiem a adoção de soluções que minimizem o consumo e possibilitem o reúso da água como forma de diminuir a demanda pelo abastecimento público e de reduzir o volume de esgoto sanitário enviado para a rede de coleta.

O projeto de revisão da NBR 5626 (ABNT, 2016) não contempla o sistema predial de água não potável, porém recomenda em "Fontes de abastecimento" que, quando existir, deve ser totalmente independente daquele destinado ao uso da água potável e que é vedada qualquer possibilidade de conexão cruzada entre ambos. Também, na seção "Proteção sanitária da água potável”, recomenda que os sistemas projetados não podem afetar a qualidade da água, particularmente por meio de interligação entre tubulações que conduzam água potável e água não potável.

Considerando que os requisitos de desempenho apresentados na NBR 15575 (ABNT, 2013) são insuficientes para a garantia de qualidade dos SPANP, Castilho (2016) desenvolveu um conjunto de requisitos de desempenho para sistemas prediais de água não potável. Para tanto, foram analisados os requisitos de desempenho apresentados por Peixoto (2008) e Paula (2005) para os sistemas 
prediais de água não potável, as recomendações encontradas nas normas nacionais NBR 13969 (ABNT, 1997), NBR 15527 (ABNT, 2007) e NBR 15575 (2013), e as recomendações encontradas nas normas internacionais BS 8525-1 (BRITISH STANDARD, 2010) e BS 8515 (BRITISH STANDARD, 2009).

Esse conjunto foi organizado em três grupos: requisitos do subsistema de coleta de efluente, requisitos do subsistema de suprimento de água não potável e requisitos relacionados às condições de exposição, os quais orientaram as entrevistas realizadas nas visitas dos seis estudos de caso. Castilho (2016) apresenta o detalhamento desses requisitos e respectivos critérios de desempenho utilizados para embasamento do questionário aplicado nos estudos de caso.

\section{Avaliação durante operação (ADO)}

A Avaliação Pós-Ocupação (APO) é uma ferramenta de avaliação do ambiente construído que permite a melhoria da qualidade dos edifícios, por meio da retroalimentação de informações, em todo o ciclo de produção deles (ARAUJO, 2004).

No caso de sistemas prediais especificamente, que devem ser avaliados em pleno funcionamento, adota-se a Avaliação Durante Operação (ADO), metodologia proposta por Almeida (1994) a partir dos conceitos de APO indicativa, investigativa e de diagnóstico, de qualidade e flexibilidade dos sistemas, de usuários-chave e critérios de desempenho. De acordo com Almeida (1994), a ADO é uma metodologia que visa avaliar e propor soluções para os sistemas prediais em operação, além de gerar elementos de retroalimentação dos processos de criação, implantação e utilização dos sistemas prediais.

Considerando que a metodologia da ADO se apresenta como uma ferramenta adequada para a avaliação de sistemas prediais de água não potável nas etapas de uso, operação e manutenção, ela é empregada para atender ao objetivo deste estudo.

\section{Método}

O método ADO é uma ferramenta de investigação de sistemas do ambiente construído em operação, por isso o estudo de caso foi considerado o método mais adequado para esta pesquisa.

A metodologia ADO apresentada por Almeida (1994) é dividida em seis etapas, descritas a seguir.

\section{Etapa 1: levantamento documental}

Esta etapa visa obter informações relativas à concepção, execução e vida do edifício analisado.
A partir delas é possível realizar análises para detectar a origem de patologias, que servem de base para a etapa de análise e diagnóstico.

\section{Etapa 2: levantamento cadastral}

Esta etapa tem como objetivo obter dados de campo, dos sistemas em operação, para auxiliar a etapa de análise e diagnóstico. Almeida (1994) recomenda, para a aplicação da etapa de levantamento cadastral, que seja realizada a análise do material obtido no levantamento documental e que seja selecionada uma equipe de campo adequada.

\section{Etapa 3: levantamento das necessidades dos usuários}

Para o levantamento das necessidades dos usuários dos sistemas prediais são aplicados questionários para obter dados relativos aos usuários dos sistemas, a interação entre usuário e sistema, e sua relação com as instalações do edifício.

\section{Etapa 4: análise e diagnóstico}

Nesta etapa são analisadas as informações obtidas nas etapas anteriores para identificar as patologias dos sistemas e suas origens, bem como avaliar as possibilidades de melhoria. Os dados obtidos no levantamento cadastral e no levantamento das necessidades dos usuários permitem comparar os dados de projeto com o executado e em operação, traçar um perfil do tipo de utilização dos sistemas prediais e determinar sua capacidade em atender às exigências dos usuários.

\section{Etapa 5: plano de recuperação}

A etapa de plano de recuperação, subsequente à identificação de patologias, pressupõe a participação dos usuários para aprovar as ações corretivas, propostas pela equipe técnica.

Vale ressaltar que, sendo este um estudo de casos múltiplos, considerou-se inviável a aplicação da ADO por completo, por pressupor a proposição de um plano de recuperação para cada edifício analisado. Assim, optou-se por realizar uma adaptação da metodologia de ADO, substituindose a etapa de plano de recuperação, caso a caso, por uma análise de validação das proposições estabelecidas para a pesquisa.

\section{Etapa 6: avaliação de resultados e retroalimentação do processo}

De acordo com Almeida (1994), a equipe que desenvolve o trabalho de $\mathrm{ADO}$ deve realizar ao 
menos uma verificação final, a fim de comparar os resultados obtidos com os inicialmente esperados e, desse modo, fazer a retroalimentação do processo.

Foram delimitadas, a partir do referencial teórico definido, as questões e as proposições a serem investigadas e validadas por meio de técnica analítica de explanação de cada estudo de caso.

As questões investigadas são:

(a) como estão operando os SPANP em edifícios residenciais no contexto atual?

(b) quais as justificativas para esse cenário?

(c) quais aspectos devem ser revistos e melhorados?

Tendo sido estabelecidas as questões abordadas, definiu-se a unidade de análise da pesquisa: o edifício residencial, por se entender que as evidências coletadas em uma amostra de edifícios residenciais permitem maior grau de generalização de resultados do que as evidências de um único edifício. Assim, optou-se por uma abordagem de replicação em estudo de casos múltiplos.

\section{Planejamento dos casos}

Os critérios utilizados para a seleção dos edifícios foram a disponibilidade de acesso à unidade para a realização da coleta de dados e as características do empreendimento, para viabilizar a replicação literal e teórica no estudo dos casos.

Foram selecionados seis empreendimentos da cidade de São Paulo com diferentes tipos de SPANP. Um empreendimento tem como fonte águas residuárias cinzas e negras em esgoto misto, dois empreendimentos utilizam água pluvial como fonte, um utiliza como fontes água residuária cinza, água subterrânea e água pluvial, e os outros dois utilizam como fontes a água subterrânea e a água pluvial.

Como técnicas de coleta de dados foram utilizadas entrevistas semiestruturadas, aplicadas face a face com usuários e operadores do sistema, representantes de construtoras e instituições de análise laboratorial, análise documental, nos casos em que o material foi disponibilizado, e observações diretas (YIN, 2010) e assistemáticas (BONI; QUARESMA, 2005) durante as visitas de campo.

O questionário aplicado por meio de entrevista durante as visitas aos edifícios selecionados foi elaborado de acordo com a metodologia de ADO, a fim de se obterem o levantamento cadastral e o levantamento de necessidades dos usuários do sistema. Por meio desse questionário procurou-se identificar o processo de gerenciamento e a rotina de manutenção do sistema, sua eficiência, as percepções de usuários e gestores.

\section{Condução do teste piloto}

Uma primeira visita de campo foi realizada com o objetivo de testar o procedimento estabelecido pelo protocolo de estudo e o questionário utilizado em entrevistas. A partir dos dados coletados no teste piloto, procedeu-se à revisão do questionário aplicado, a fim de aperfeiçoar as variáveis de controle.

\section{Coleta de dados}

Conforme estabelecido em protocolo de estudo, durante as visitas foram realizadas as observações diretas e as entrevistas. O registro desses dados foi feito por meio de anotações em campo e registros fotográficos. O levantamento documental foi solicitado verbalmente, tendo sido registrado por meio de fotocópia ou arquivo digitalizado.

\section{Análise dos dados}

A partir dos dados coletados elaborou-se uma narrativa de cada condomínio visitado. Para a realização da análise geral das evidências e replicação dos tópicos investigados fez-se necessária a redução dos dados. Para tanto, foram estabelecidas categorias, de acordo com as propriedades teóricas associadas à pesquisa.

As narrativas foram, então, divididas em partes conforme a categoria teórica abordada e identificadas pelos respectivos códigos. Essa divisão permitiu a representação visual do conjunto de informações coletadas por meio de um painel demonstrativo. Nesse painel as classificações que correspondem a um item favorável ao desempenho adequado do sistema e segurança do usuário foram identificadas com a cor verde (classificação “conforme”). As classificações que representam uma não conformidade de desempenho ou risco aos usuários foram identificadas com a cor vermelha (classificação "não conforme”). Os itens classificados como "não foi possível verificar" são identificados com a cor amarela, e os apontados como "não se aplica” com a cor cinza.

A partir da comparação dos painéis individuais realizou-se uma análise cruzada dos casos, identificando-se as convergências e divergências entre os dados coletados. Por meio do cruzamento dos dados analisados com o conteúdo, previamente levantado na literatura, aplicou-se a etapa de análise e diagnóstico, prevista na metodologia de ADO. 
Conforme mencionado anteriormente, uma vez que este estudo realiza a ADO para mais de um edifício, optou-se por, na etapa de plano de recuperação, apresentar uma análise de validação das proposições estabelecidas para a pesquisa. Pretende-se, desse modo, concluir a análise dos dados com a retroalimentação de informações técnicas que possam servir de referência para projetistas, executores e gestores que atuam com sistemas prediais de água não potável.

\section{Estudos de caso}

A pesquisa de campo foi conduzida em seis condomínios residenciais da cidade de São Paulo, os quais são apresentados a seguir. Uma primeira visita foi realizada ao empreendimento do estudo de caso “A” para realização do teste piloto. Uma vez revisados o protocolo de pesquisa e o questionário, com base na experiência do teste piloto, os demais condomínios foram visitados.

\section{Estudo de caso A}

Trata-se de um condomínio com sete torres de vinte e oito andares. Os dois subsolos de garagem são comuns a todas as torres. São dois apartamentos por andar, de 156 a 234 m², em um total de 392 unidades e população aproximada de 1.500 pessoas.

O sistema predial de água não potável foi executado pela construtora e entrou em operação em 2013. As fontes de abastecimento do SPANP são: água cinza coletada de chuveiros, lavatórios e de máquinas de lavar roupas; água subterrânea, proveniente dos poços de drenagem do subsolo; e água pluvial, coletada nos reservatórios de retenção para atendimento à Lei ${ }^{\circ} 13.276$ (SÃO PAULO, 2002). A água cinza e a água subterrânea recebem tratamento e filtração, e a água pluvial somente filtração. Todo o volume de água não potável recebe adição de corante na cor azul.

$\mathrm{O}$ acesso ao reservatório inferior de água não potável é feito por uma abertura, sem tampa, na parte superior. Caso ocorra falha no sistema de tratamento ou produção insuficiente de água não potável, há um ponto de fornecimento de água potável que pode ser utilizado para abastecer o sistema.

Com relação à comunicação visual, não há uma cor diferenciada para o SPANP, e foram observados trechos de tubulação de água não potável de cor verde, a mesma cor utilizada para a tubulação de água potável.

O gerenciamento e a manutenção do SPANP são feitos por uma empresa terceirizada, que realiza a manutenção preventiva mensalmente. A cada três meses são coletadas amostras de água para análise de qualidade, mas não há evidências dessa prática.

Alguns casos de conexão cruzada ocorreram quando moradores instalaram ducha higiênica nos banheiros a partir do ramal das bacias sanitárias, alimentadas por água não potável. O corante azul da água não potável permitiu a identificação do problema em um teste do SPANP.

Os dados de impacto de redução de consumo de água potável apresentados são estimativos e não foram disponibilizados pelo condomínio. Não há também gerenciamento do consumo de energia elétrica para o SPANP, o que não permite avaliar o impacto do SPANP no consumo de energia do condomínio.

\section{Estudo de caso B}

Trata-se de um condomínio de oito casas e cerca de 31 habitantes. No projeto das oito casas os leiautes do banheiro e da cozinha seguem o conceito de módulo e estão posicionados junto a shafts de fácil acesso, onde são concentradas as tubulações de água potável e não potável. Não há comunicação visual para os dois sistemas, que apresentam o mesmo tipo de tubulação, cor e diâmetro tanto para água potável como para água não potável.

O SPANP entrou em operação em 2011 e são utilizadas como fonte de abastecimento as águas residuárias, compostas de águas cinzas e negras, e a água subterrânea captada de um poço. Apenas as águas residuárias passam por sistema de tratamento. Após o tratamento a água não potável não recebe corante e é utilizada nas descargas das bacias sanitárias, limpeza de pisos de áreas comuns e irrigação de jardins e horta coletiva. As águas pluviais não são aproveitadas.

O gerenciamento do SPANP-R é realizado pelo zelador do condomínio com o auxílio de uma moradora que assumiu a administração geral do empreendimento. Não é realizada manutenção preventiva no sistema, apenas a corretiva.

O condomínio não controla a qualidade da água não potável, e em 2015 os moradores observaram que a água não potável passou a apresentar cor e odor desagradáveis, deixando manchas na louça das bacias sanitárias. Por esse motivo amostras de água foram coletadas e enviadas para análise laboratorial segundo os parâmetros estabelecidos pela NBR 13969 (ABNT, 1997), para Classe 1 de uso. Trata-se da classe mais restritiva dessa norma, por ter como objeto o uso da água em atividades que requerem contato direto do usuário ou aspiração de aerossóis. De acordo com o laudo, as 
amostras apresentaram não conformidade para os parâmetros sólidos dissolvidos totais e coliformes termotolerantes.

Foi relatada a suspeita de uma conexão cruzada em uma das residências. Os proprietários instalaram uma ducha higiênica ao lado da bacia sanitária em um dos banheiros da casa e notaram que o equipamento sanitário recém-instalado ficou sem fornecimento de água durante o período em que o SPANP-R estava desligado para manutenção.

O condomínio não faz o gerenciamento do consumo de água nem de energia elétrica, o que não possibilita a análise do impacto de redução ou não desses insumos.

\section{Estudo de caso C}

Trata-se de um condomínio com duas torres de 22 andares, quatro apartamentos por andar com área de $142 \mathrm{~m}^{2}$, totalizando 176 unidades habitacionais e população estimada de 598 habitantes.

O sistema predial de água não potável entrou em operação em 2014. As fontes de abastecimento são água subterrânea, captada dos reservatórios de retenção que o edifício é obrigado a ter em atendimento à Lei n ${ }^{\circ} 13.276$ (SÃO PAULO, 2002), e água pluvial, coletada da cobertura e dos pisos do condomínio.

Após tratamento, as águas subterrânea e pluvial passam por um filtro de areia e recebem adição automática de cloro. Em seguida, a água não potável é conduzida diretamente para os pontos de utilização, uma vez que não há reservatório de água não potável. Esta água é utilizada na lavagem das garagens e áreas comuns. Não existe também a possibilidade de utilização de água potável no SPANP caso esse sistema apresente falha.

Com relação à comunicação visual, a tubulação de água não potável é de cor roxa, diferentemente das demais tubulações do sistema predial de água potável. Os pontos de utilização de água não potável, com etiquetas que alertam para a qualidade da água, são de acesso restrito e permanecem com cadeados. São utilizados apenas pela equipe de manutenção do condomínio.

O gerenciamento do SPANP é realizado pelo zelador e por um auxiliar de manutenção, com acompanhamento da empresa que executou o sistema. Até o momento o condomínio não realizou nenhum tipo de controle da qualidade da água produzida no local e também não foi adicionado corante à água não potável.

O condomínio não faz o gerenciamento do consumo de água nem de energia elétrica, o que não possibilita a análise do impacto de redução ou não desses insumos.

\section{Estudo de caso D}

Trata-se de uma residência unifamiliar com área de $400 \mathrm{~m}^{2}$, quatro dormitórios e sete banheiros. A família é composta de quatro pessoas. O sistema predial de água não potável entrou em operação em 2010 tendo como fonte apenas a água pluvial. A água não potável, enquanto o sistema operou, era utilizada nas bacias sanitárias e na irrigação do jardim.

O sistema coletava água pluvial somente da cobertura e não previa o descarte automático da água coletada nos primeiros minutos de chuva. Os moradores desligavam o sistema apenas durante a primeira chuva, após um período de estiagem.

O reservatório inferior, com capacidade de 10.000 l, está a $1 \mathrm{~m}$ abaixo do nível do solo, pois a limpeza do reservatório foi prevista a cada 10 anos. Ressalta-se que não foi construída a tampa de acesso para a manutenção desse reservatório. Considerando-se que o sistema entrou em operação em 2010, a primeira manutenção só ocorreria em 2020. Por ter sido desativado em 2014, após quatro anos de operação, não passou pela limpeza ou inspeção programada.

Com relação à comunicação visual, não há diferenciação por cor e foi utilizada tubulação de PVC tanto para água potável como para água não potável. Os registros e as torneiras do SPANP-P apresentam identificação do tipo de água oferecido.

O gerenciamento e a manutenção, com exceção do reservatório inferior, foram realizados enquanto o sistema estava em operação. Era feita a limpeza do filtro e dos reservatórios superiores, bem como a adição de cloro nesses reservatórios uma vez ao ano. Pouco tempo depois de iniciada a operação do sistema, a adição de cloro foi suspensa, por considerarem que a qualidade da água coletada dispensava desinfecção.

O controle da qualidade da água não potável nunca foi realizado, e os moradores não faziam adição de corante na água para diferenciá-la da água potável. Os usuários não detectaram vazamento, conexão cruzada ou situação de contaminação da água potável pela água não potável.

Os moradores preferiram desativar esse sistema em 2014 devido a uma falha do conjunto motorbomba do reservatório inferior, que impossibilitou o bombeamento da água para o reservatório superior. A correção do conjunto motor-bomba implica escavar o jardim até o nível do reservatório de concreto, o que inviabiliza a atividade. 
Com relação ao gerenciamento do consumo de água, os moradores verificaram que em 2015, mesmo não utilizando o sistema predial de água não potável, economizaram um volume maior de água potável do que quando o sistema de água não potável esteve em operação. Isso mostra que as medidas economizadoras adotadas a partir de 2014, por motivo da crise hídrica, geraram maior impacto do que a adoção de uma fonte alternativa de água.

\section{Estudo de caso E}

Trata-se de um condomínio com 264 unidades habitacionais composto de quatro torres de apartamentos com 22 andares, sendo duas torres com dois apartamentos de $170 \mathrm{~m}^{2}$ por andar. As duas outras torres apresentam quatro apartamentos por andar, sendo uma com apartamentos de $133 \mathrm{~m}^{2}$ e outra com apartamentos de $115 \mathrm{~m}^{2}$. A população estimada é de 898 habitantes.

O empreendimento foi entregue pela construtora em 2006. A implantação do sistema predial de água não potável, em 2014, foi motivada pela crise hídrica, quando foi instalada uma bomba no reservatório de retenção de água pluvial que o edifício possui, em atendimento à Lei $\mathrm{n}^{0} 13.276$ (SÃO PAULO, 2002), para aproveitar essa água. Além da água pluvial coletada de coberturas e pisos, é também utilizada a água proveniente da lavagem dos filtros da piscina, por considerarem que o cloro presente nesta água auxilia na desinfecção do efluente armazenado.

A água não potável não recebe nenhum tipo de tratamento e é utilizada na lavagem de pisos das áreas comuns. Essas atividades são realizadas por meio de uma mangueira ligada diretamente a um conjunto motor-bomba; portanto, não houve alteração nas tubulações do sistema existente. Assim, as tubulações de água pluvial permaneceram com a cor marrom, as de água potável com a cor verde, e as de coleta de esgoto com a cor preta. Não há distinção por cor para a tubulação do sistema de água não potável. A água não recebe adição de corante para diferenciá-la da água potável e não passa por monitoramento ou controle de qualidade.

O gerenciamento do sistema é realizado pelo zelador, que não faz manutenção preventiva. Em situações de falha no conjunto motor-bomba, a empresa contratada para a manutenção geral do condomínio é acionada para a correção do problema. A limpeza do reservatório é realizada anualmente por empresa terceirizada.

O condomínio não faz o gerenciamento do consumo de água nem de energia elétrica, o que não possibilita a análise do impacto de redução ou não desses insumos.

\section{Estudo de caso F}

Trata-se de um condomínio residencial com duas torres de 28 andares e dois apartamentos por andar, de $237 \mathrm{~m}^{2}$, e população estimada de 380 habitantes.

O empreendimento foi entregue em 2011, e o sistema predial de água não potável foi instalado em 2013, tendo em vista aproveitar a água subterrânea e também a água pluvial. A água pluvial é captada do reservatório de retenção em atendimento à Lei ${ }^{\circ} 13.276$ (SÃO PAULO, 2002) e não é misturada com a água subterrânea. A água pluvial é coletada das superfícies de cobertura e dos pisos do condomínio. A água não potável é utilizada na limpeza de áreas comuns e na irrigação de jardim.

As águas não potáveis coletadas, de fonte subterrânea e pluvial, recebem adição de cloro a cada dois meses e não há nenhum outro tipo de tratamento adicional. Os reservatórios de água não potável não apresentam ponto de entrada de água potável para abastecimento em caso de falha no SPANP.

Os pontos de utilização são de acesso restrito aos funcionários do condomínio, porém foram registradas torneiras com os volantes instalados e sem restrição de acesso. Também não há sinalização ou identificação nos pontos de utilização abastecidos com água não potável. Essa água não recebe adição de corante para diferenciála da água potável.

O gerenciamento do sistema é realizado pelo gerente predial, que afirmou manter rotina de manutenção preventiva, realizada mensalmente por empresa terceirizada. A limpeza do sistema é realizada mensalmente, por uma segunda empresa, responsável também pela limpeza dos filtros da piscina. Não é feito o esvaziamento e desinfecção dos reservatórios nem o monitoramento da qualidade da água não potável.

Não foi identificada nenhuma situação de vazamento na tubulação, conexão cruzada ou contaminação da água potável pela água não potável.

O condomínio não faz o gerenciamento do consumo de água nem de energia elétrica, o que não possibilita a análise do impacto de redução ou não desses insumos. 


\section{Resultados e discussão}

A partir das informações obtidas nos estudos de caso dos SPANP foram estabelecidas seis categorias que permitiram a redução dos dados e a análise geral de evidências, quais sejam: fonte de água, sistema de tratamento, instalações, pontos de utilização, operação e usuários.

Os estudos de caso foram divididos em partes, de acordo com a classificação nas categorias, e dispostos no painel demonstrativo apresentado no Quadro 1.

Ao analisar o Quadro 1, verifica-se que há mais não conformidades de desempenho e de risco à segurança dos usuários nos empreendimentos analisados que conformidades. Algumas dessas não conformidades, inclusive, estão presentes em todos os estudos de caso. A identificação de água não potável ao longo das tubulações que transportam água dessa qualidade é um desses itens, pois não foi encontrada em nenhum dos SPANP visitados.

Na categoria “fonte de água” observa-se que, entre os cinco condomínios que utilizam água pluvial, nenhum dispõe de sistema automático para descarte da primeira água de chuva que escoa na superfície coletora e que somente um condomínio usa exclusivamente a água coletada da cobertura. Nos demais o efluente pluvial é proveniente da água coletada nas áreas de coberturas e pisos, ao contrário do que é recomendado pela NBR 15527 (ABNT, 2007).

Observa-se nessa categoria que o uso de água pluvial proveniente de pisos pode ter dejetos de animais, e quando utilizada sem tratamento específico pode colocar em risco a saúde do usuário em atividades como lavar pisos, por ter contato direto com este.

Na categoria "sistema de tratamento" verifica-se que dois dos condomínios não possuem sistema de tratamento para o efluente coletado. Entre os que possuem estação de tratamento, constatou-se em um deles, com base nos resultados laboratoriais da qualidade da água, que a água não potável apresentava qualidade inferior à necessária para as atividades realizadas segundo os parâmetros estabelecidos pela NBR 13969 (ABNT, 1997). Para os demais não há dados suficientes que permitam essa avaliação.

Ressalta-se que o sistema de tratamento depende dos efluentes, que, por sua vez, dependem das atividades realizadas no edifício. Como elas variam diariamente, é necessária uma gestão da qualidade sistemática, o que em geral não ocorre nos casos estudados.
No que se refere à categoria "instalações", pode-se afirmar que em três condomínios não há no reservatório de água não potável componente que permita abastecê-lo com água potável em caso de falha ou de manutenção do SPANP. Entre os condomínios que contam com ponto de abastecimento de água potável no reservatório de água não potável, um não possui componente antirrefluxo da água não potável no ponto de abastecimento de água potável; nos demais não foi possível evidenciar tal situação. Todos os sistemas apresentam extravasor, que descarta o excedente de água não potável na rede pública de coleta e transporte de esgoto sanitário.

Com relação à diferenciação da tubulação de água não potável por cor, apenas um dos condomínios utiliza tubulação roxa para o SPANP. Apenas um dos condomínios tem diferenciação de pontos de utilização do SPANP por cor. Em somente um deles há torneiras com formato diferente nos pontos abastecidos por água não potável. Três dos seis condomínios sinalizaram os pontos de utilização, com alerta para a qualidade distinta de água, e somente um deles mantém restrição de acesso à água não potável.

Nesta categoria, considera-se como grave a não identificação de pontos de utilização e de tubulações e conduzem água não potável, além da ausência de componentes antirrefluxo, que propiciam a ocorrência de conexão cruzada, evidenciada nos casos A e B. No caso A esta só foi evidenciada devido ao corante. Ressalta-se que nenhum dos outros condomínios adicionam corante à água não potável.

Na categoria "pontos de utilização" três condomínio destinam a água não potável à descarga de bacias sanitárias, quatro a utilizam para limpeza de pisos, e quatro realizam a irrigação de jardins. A maioria dos edifícios usam a água não potável em mais de uma atividade, e dois deles destinam a água a apenas uma atividade.

Na categoria “operação” pode-se afirmar que apenas um dos condomínios realiza a adição regular de corante à água não potável. Em três deles é feita a manutenção preventiva, e nos demais apenas a corretiva.

O gerenciamento do sistema, na maioria das vezes, é feito pelo zelador ou por um funcionário do condomínio, o que foi registrado em quatro condomínios. Apenas um deles tem uma empresa especializada para a realização do gerenciamento, e em outro a responsabilidade foi assumida por morador e proprietário do imóvel. 
Quadro 1 - Painel demonstrativo do cenário geral dos SPANP dos edifícios estudados

\begin{tabular}{|c|c|c|c|c|c|c|c|c|}
\hline \multirow{2}{*}{ Categorias } & \multicolumn{2}{|r|}{ Subcategorias } & \multicolumn{6}{|c|}{ Estudos de caso } \\
\hline & Código & Descrição & A & B & C & D & $E$ & $\mathrm{~F}$ \\
\hline \multirow{4}{*}{$\begin{array}{l}\text { Fonte de } \\
\text { água }\end{array}$} & 1 & Fonte de abastecimento do SPANP & $\mathrm{CZ}+\mathrm{SB}+\mathrm{PL}$ & $\mathrm{CZ}+\mathrm{NG}+\mathrm{SB}$ & $\mathrm{SB}+\mathrm{PL}$ & $\mathrm{PL}$ & $\mathrm{PL}$ & $\mathrm{SB}+\mathrm{PL}$ \\
\hline & $\|$ & $\begin{array}{l}\text { Desc arte automático da primeira água de coleta } \\
\text { SPANP-P }\end{array}$ & & & & & & \\
\hline & III & Restrição da área de coleta à cobertura SPANP-P & & & & & & \\
\hline & IV & $\begin{array}{l}\text { Alteraç ão da fonte de abastecimento durante } \\
\text { operaç ão }\end{array}$ & & & & & & \\
\hline \multirow{3}{*}{$\begin{array}{l}\text { Sistema de } \\
\text { tratam ento }\end{array}$} & 1 & Sistema de tratam ento de água existente & & & & & & \\
\hline & $\|$ & Sistema de tratam ento de água adequado & & & & & & \\
\hline & III & $\begin{array}{l}\text { Sistema de tratam ento de água executado por } \\
\text { empresa espec ializada }\end{array}$ & & & & & & \\
\hline \multirow{6}{*}{ Instalações } & 1 & $\begin{array}{l}\text { Completa separaç ão dos sistemas prediais de água } \\
\text { potável e não potável }\end{array}$ & & & & & & \\
\hline & ॥ & Tubulação do SPANP de cor diferente & & & & & & \\
\hline & III & Tubulação do SPANP identificada & & & & & & \\
\hline & IV & $\begin{array}{l}\text { Reservatório de água não potável c om alimentação } \\
\text { de água potável para back up }\end{array}$ & & & & & & \\
\hline & $\mathrm{v}$ & $\begin{array}{l}\text { Reservatório de água não potável com componente } \\
\text { de prevenção de refluxo no abastec imento de água } \\
\text { potável }\end{array}$ & & & & & & \\
\hline & $\mathrm{Vl}$ & Reservatório de água não potável c om extravasor & & & & & & \\
\hline \multirow{5}{*}{$\begin{array}{l}\text { Pontos de } \\
\text { utilizaçãa }\end{array}$} & 1 & Atividade de destino da água não potável & BS & $B S+L P+I J$ & $\mathrm{LP}+\mathrm{IJ}$ & $\mathrm{BS}+\mathrm{IJ}$ & $\mathrm{LP}$ & $L P+I J$ \\
\hline & $\|$ & Pontos de utilização do SPANP com cor diferente & & & & & & \\
\hline & III & $\begin{array}{l}\text { Pontos de utilização do SPANP com formato } \\
\text { diferente }\end{array}$ & & & & & & \\
\hline & IV & Pontos de utilização com sinalização & & & & & & \\
\hline & $\mathrm{V}$ & Pontos de utilização com acesso restrito & & & & & & \\
\hline \multirow{13}{*}{ Operação } & I & Adição de corante à água não potável & & & & & & \\
\hline & II & Realização de manutenção preventiva & & & & & & \\
\hline & III & Responsável pelo gerenciamento do sistema & EC & $\mathrm{MO}+\mathrm{FC}$ & FC & $\mathrm{MO}$ & FC & FC \\
\hline & IV & Controle periódico de qualidade da água não potável & & & & & & \\
\hline & v & Identific ação de ocorrência de conexão cruzada & & & & & & \\
\hline & $\mathrm{Vl}$ & Identific ação de ocorrência de vazamento & & & & & & \\
\hline & VI & Identific ação de ocorrência de entupimento & & & & & & \\
\hline & VIII & $\begin{array}{l}\text { Identific ação de ocorrência de contaminação da } \\
\text { água potável pela água não potável }\end{array}$ & & & & & & \\
\hline & $\mathrm{IX}$ & $\begin{array}{l}\text { Identific ação de ocorrência de produção de água } \\
\text { não potável com qualidade inadequada }\end{array}$ & & & & & & \\
\hline & $x$ & $\begin{array}{l}\text { Disponibilidade de cartilha com informações } \\
\text { téc nicas para operadores do SPANP }\end{array}$ & & & & & & \\
\hline & $\mathrm{XI}$ & $\begin{array}{l}\text { Disponibilidade de cartilha com informações } \\
\text { téc nicas para usuários do SPANP }\end{array}$ & & & & & & \\
\hline & XII & Controle de consumo de energia elétric ado SPANP & & & & & & \\
\hline & XIII & Controle de economia de consumo de água potável & & & & & & \\
\hline \multirow{2}{*}{ Usuánios } & 1 & Grau de confiabilidade no sistema & $\mathrm{AL}+\mathrm{MD}$ & $\mathrm{AL}$ & $A L+M D+M D$ & $\mathrm{MD}$ & $\mathrm{AL}+\mathrm{MD}$ & MD \\
\hline & $\|$ & Preocupação com a água potável & NIL & QA & $\mathrm{NIL}+\mathrm{NIL}+\mathrm{NIL}$ & NIL & $\mathrm{QA}+\mathrm{TD}$ & $\mathrm{CC}$ \\
\hline \multirow[t]{10}{*}{$\begin{array}{l}\text { Notas: } \\
\text { Legenda: }\end{array}$} & & Conforme & & BS & Bacia sanitária & & & \\
\hline & & Não conforme & & MO & Morador / usuár & & & \\
\hline & & Não foi pos sivel verific ar por falta de dados suficientes & & FC & Func ionário / ze & ador & & \\
\hline & & Não se aplica & & EC & Empresa espec & alizada c ontratad & & \\
\hline & PL & Água pluvial & & $\mathrm{AL}$ & Alta & & & \\
\hline & $\mathrm{CZ}$ & Água cinza & & MD & Média & & & \\
\hline & NG & Água negra & & NIL & Nenhuma & & & \\
\hline & SB & Água suberrânea & & TD & Transm issão de & doenç as & & \\
\hline & $\mathrm{LP}$ & Lavagem de piso & & QA & Qualidade da ác & la não potável & & \\
\hline & IJ & Irrigação de jardim & & $\mathrm{cc}$ & Conexão cruzac & & & \\
\hline
\end{tabular}

O controle de qualidade da água, com análise laboratorial periódica de amostras de água coletadas no sistema, é realizado em dois dos condomínios. Em um deles esta análise faz parte do serviço de gerenciamento contratado de empresa especializada nesse tipo de sistema. Ressalta-se que nenhum evidenciou a realização dessa ação. 
Com relação ao impacto de redução de consumo de água potável, em apenas um dos condomínios foi possível obter valores documentados de consumo. Nenhum dos condomínios realiza o gerenciamento de consumo de água ou de energia elétrica dos dois tipos de sistema: água potável e não potável.

No que se refere a ocorrências e irregularidades identificadas no SPANP durante sua operação, dois condomínios relataram a detecção de conexão cruzada, um apresentou vazamento, e em dois condomínios foi verificada água não potável com qualidade inadequada àquilo a que se destina.

Nenhum dos condomínios dispõe de cartilha ou manual técnico com informações que orientem gestores e operadores sobre a operação e manutenção do sistema. Também não existe cartilha ou manual com orientações aos usuários do sistema.

Nesta categoria, considera-se como crítica a ausência de empresa especializada para a gestão da qualidade e da quantidade; qualidade sob o enfoque sanitário e quantidade para verificar se realmente o sistema está consumindo menos água e energia, razão pela qual, em geral, os condomínios são estimulados ao SPANP.

Com relação à categoria “usuários”, pode-se afirmar que a percepção que os usuários têm do SPANP é positiva, uma vez que quatro dos dez entrevistados, representantes dos condôminos, avaliaram como alto o grau de confiabilidade, e os seis restantes avaliaram como médio.

Ao serem perguntados sobre preocupações que têm com a utilização de água não potável, cinco de nove entrevistados afirmaram não existir nenhuma preocupação por parte dos usuários, dois apontaram preocupação com a qualidade da água não potável, um com o risco de transmissão de doenças, e um com o risco de conexão cruzada.

Comparando-se as evidências coletadas nas visitas de campo, é possível constatar que o cenário atual dos SPANP dos edifícios avaliados é caracterizado pelo não atendimento de grande parte dos requisitos de desempenho e de risco à segurança dos usuários.

\section{Conclusões}

A avaliação durante operação realizada em seis condomínios permite retratar que os sistemas de água não potável dos edifícios residenciais avaliados apresentam diversas não conformidades desde as fases de projeto e execução até o processo de gerenciamento, operação e manutenção.
Cinco dos seis casos estudados apresentaram ao menos uma ocorrência de irregularidade no sistema, dois deles envolvendo qualidade inadequada da água produzida e dois com conexão cruzada. Ressalta-se que a não identificação de outras irregularidades nos SPANP dos condomínios estudados não é necessariamente um indicador de que tudo esteja operando adequadamente, e sim incapacitação técnica de detectar problemas.

A utilização da ADO em SPANP permite a realização de uma avaliação sobre a adequabilidade e a qualidade desses sistemas, o que contribui para a melhoria contínua e responsável do uso de água não potável, principalmente em edifícios residenciais.

Assim, conclui-se que a capacitação técnica, normas técnicas e legislações específicas que orientem projetistas, executores, gestores e usuários podem contribuir para a melhoria do cenário encontrado nos SPANP estudados, os quais estão operando com desempenho inferior ao adequado e colocando em risco a saúde dos usuários.

\section{Referências}

ALMEIDA, G. G. Avaliação Durante Operação

(ADO): metodologia aplicada aos sistemas prediais. São Paulo, 1994. 185 f. Dissertação (Mestrado em Engenharia Civil) - Escola Politécnica, Universidade de São Paulo, São Paulo, 1994.

\section{ARAB COUNTRIES WATER UTILITY ASSOCIATION. Wastewater Reuse in Arab}

Countries: comparative compilation of information and reference list. Jordan, 2010. (ACWUA Working Group). Disponível em: <http://www.ais.unwater.org/ais/pluginfile.php/ 356/mod_page/content/119/Jordan_SummaryReport-CountryCasestudies_final.pdf $>$. Acesso em: 16 mar. 2014.

ARAUJO, L. S. M. Avaliação Durante Operação dos Sistemas Prediais Hidráulicos e Sanitários em Edifícios Escolares. Campinas, 2004. 245 f. Dissertação (Mestrado em Engenharia Civil) Faculdade de Engenharia Civil, Arquitetura e Urbanismo da Universidade Estadual de Campinas, Campinas, 2004.

ASSOCIAÇÃO BRASILEIRA DE NORMAS TÉCNICAS. NBR 15575: edificações habitacionais: desempenho. Rio de Janeiro, 2013. 
ASSOCIAÇÃO BRASILEIRA DE NORMAS TÉCNICAS. Projeto de Revisão da NBR 5626: sistemas prediais de água fria e quente: procedimento. Rio de Janeiro, 2016.

\section{ASSOCIAÇÃO BRASILEIRA DE NORMAS} TÉCNICAS. NBR 13969: tanques sépticos: unidades de tratamento complementar e disposição final dos efluentes líquidos: projeto, construção e operação. Rio de Janeiro, 1997.

\section{ASSOCIAÇÃO BRASILEIRA DE NORMAS}

TÉCNICAS. NBR 15527: água de chuva: aproveitamento de coberturas em áreas urbanas para fins não potáveis: requisitos. Rio de Janeiro, 2007.

BONI, V.; QUARESMA, S. J. Aprendendo a Entrevistar: como fazer entrevistas em Ciências Sociais. Em Tese, v. 2, n. 1, p. 68-80, jan./jul. 2005.

BRITISH STANDARD INSTITUTION. BS 85251: greywater systems. London, 2009.

BRITISH STANDARD INSTITUTION. BS 8515: rainwater harvesting systems: code of practice. London, 2010.

CASTILHO, C. P. Avaliação Durante Operação de Sistemas Prediais de Água Não Potável. São Paulo, 2016. 261 f. Dissertação (Mestrado em Engenharia Civil) - Escola Politécnica da Universidade de São Paulo, São Paulo, 2016.

COOK, S.; SHARMA, A.; GURUNG, T. R. Evaluation of Alternative Water Sources For Commercial Buildings: a case study in Brisbane, Australia. Resources, Conservation and Recycling, v. 89, p. 86-93, 2014.

\section{MEDITERRANEAN WASTEWATER REUSE} WORKING GROUP. Mediterranean Wastewater Reuse Report. Mediterranean Wastewater Reuse Working Group, 2007. Disponível em:

$<$ http://ec.europa.eu/environment/water/waterurbanwaste/info/pdf/final_report.pdf $>$. Acesso em: 16 mar. 2014.

OLIVEIRA, L. H. O Uso de Água Não Potável em Edifícios Residenciais. Hydro, São Paulo, v. 34, p. 60-63, 2009.
OLIVEIRA, L. H. et al. Sistemas de Água Não Potável: centralizados ou descentralizados. Hydro, São Paulo, v. 88, p. 54-57, 2014.

OLIVEIRA, L. H.; MARQUES, I. G. Padronização de Terminologia e de Conceitos de Sistemas Prediais de Água Não Potável. São Paulo: CBCS, 2014.

PAULA, H. M. Sistema de Aproveitamento de Água de Chuva na Cidade de Goiânia: avaliação da qualidade da água em função do tempo de detenção no reservatório. Goiânia, 2005. 196 f. Dissertação (Mestrado em Engenharia Civil) Escola de Engenharia, Universidade Federal de Goiás, Goiânia, 2005.

PEIXOTO, L. M. Requisitos e Critérios de Desempenho Para Sistema de Água Não Potável de Edifícios Residenciais. São Paulo, 2008. 146 f. Dissertação (Mestrado) - Escola Politécnica da Universidade de São Paulo, São Paulo, 2008.

POWER, K. Recycled Water Use in Australia: regulations, guidelines and validation requirements for a national approach. Waterlines Report Series, Canberra, n. 26, 2010. Disponível em: $<$ http://archive.nwc.gov.au/_data/assets/pdf_file/0 006/10977/Recycled_water_use_in_Australia.pdf $>$ . Acesso em: 16 mar. 2014.

SÃO PAULO. Lei no 13276, de 04 de janeiro de 2002, que torna obrigatória a execução de reservatório para as águas coletadas por coberturas e pavimentos nos lotes edificados ou não, que tenham área impermeabilizada superior a $500 \mathrm{~m}^{2}$ (quinhentos metros quadrados). Brasília, 2002.

UNITED NATIONS WORLD WATER ASSESSMENT PROGRAMME. The United Nation World Development Report 2015: water for sustainable world. Paris: UNESCO, 2015.

UNITED STATES ENVIROMENTAL PROTECTION AGENCY. Guidelines For Water Reuse. Washington: U.S. Environmental Protection Agency, 2012.

YIN, R. K. Estudo de Caso: planejamento e métodos. 4. ed. Porto Alegre: Bookman, 2010. 


\section{Carolina Paula de Castilho}

Departamento de Engenharia de Construção Civil, Escola Politécnica | Universidade de São Paulo | Av. Prof. Almeida Prado n. 83, Trav. 1 Cidade Universitária | São Paulo - SP - Brasil | CEP 05508-000 | Tel.: (11) 3091-5458 | E-mail: castilho. p.carolin@gmail.com

\section{Lúcia Helena de Oliveira}

Departamento de Engenharia de Construção Civil, Escola Politécnica | Universidade de São Paulo | E-mail: lucia. helena@.usp.br

\section{Revista Ambiente Construído}

Associação Nacional de Tecnologia do Ambiente Construído

Av. Osvaldo Aranha, 99 - 3o andar, Centro

Porto Alegre - RS - Brasil

$$
\text { CEP 90035-190 }
$$

Telefone: +55 (51) 3308-4084

Fax: +55 (51) 3308-4054

www. seer. ufrgs. br/ ambienteconstruido

E-mail: ambienteconstruido@ufrgs.br 